Article

\title{
Demographic Disparities Using Ranked-Choice Voting? Ranking Difficulty, Under-Voting, and the 2020 Democratic Primary
}

\author{
Joseph A. Coll \\ Department of Political Science, University of lowa, lowa City, IA 52246, USA; E-Mail: joseph-coll@uiowa.edu
}

Submitted: 12 December 2020 | Accepted: 1 March 2021 | Published: 15 June 2021

\begin{abstract}
Ranked choice voting (RCV) has become increasingly popular in recent years, as more jurisdictions in the US adopt the voting system for local, state, and federal elections. Though previous studies have found potential benefits of RCV, some evidence suggests ranking multiple candidates instead of choosing one most preferred candidate may be difficult, with potential demographic disparities linked to age, gender, or racial or ethnic identity. Further, these difficulties have been assumed to cause individuals to improperly fill out RCV ballots, such as ranking too many or not enough candidates. This study seeks to answer three interrelated questions: 1 ) Which demographic groups find it difficult to rank candidates in RCV elections? 2) Who is more likely to cast under-voted ballots (not ranking all candidates)? 3) Is there a relationship between finding RCV voting difficult and the likelihood of casting an under-voted ballot? Using unique national survey data of 2020 Democratic primary candidate preferences, the results indicate most respondents find ranking candidates easy, but older, less interested, and more ideologically conservative individuals find it more difficult. In a hypothetical ranking of primary candidates, $12 \%$ of respondents under-voted (did not rank all options). Despite their perceived increased difficulty, older individuals were less likely to under-vote their ballot. No other demographic groups consistently experienced systematic differences in ranking difficulty or under-voting across a series of model specifications. These findings support previous evidence of older voters having increased difficulty, but challenge research assuming difficulty leads to under-voting, and that racial and ethnic groups are disadvantaged by RCV.
\end{abstract}

\section{Keywords}

Democratic primaries; elections; electoral systems; ethnic; race; ranked choice voting; United States of America

\section{Issue}

This article is part of the issue "The Politics, Promise and Peril of Ranked Choice Voting" edited by Caroline Tolbert (University of lowa, USA).

(C) 2021 by the author; licensee Cogitatio (Lisbon, Portugal). This article is licensed under a Creative Commons Attribution 4.0 International License (CC BY).

\section{Introduction}

Ranked choice voting (RCV) has become increasingly popular in the US over the last two decades, as more cities and states adopt the preferential voting method into their election systems (Fortin, 2020). In 2018, Maine used RCV for all state and federal primary elections, as well as for Congressional general elections. Two years later, four states-Alaska, Hawaii, Kansas, and Wyoming-selected their 2020 presidential Democratic nominee using RCV. As of 2020, more than fifteen cities utilized RCV for local elections, including large population centers such as San Francisco, California and New York City, New York (FairVote, 2020).
Despite the spread of RCV, most US elections operate under plurality rules with no vote thresholds where candidates can win with less than a majority the of votes so long as they have the most (but see, for example, the 2020 Senate election in Georgia). Unlike plurality elections, RCV elections require winners to obtain a majority of the vote of the ballots cast to be crowned victor. RCV allows respondents to rank all candidate preferences at one time without requiring a second election be held should no majority be reached in the first round. RCV elections provide the opportunity for voters to rank the candidates from most to least preferred, and if the voters' most preferred candidate receives the least votes, that candidate is removed, and all votes cast for them 
go to the voters' respective second choices (cf. Grofman $\&$ Feld, 2004). Eligible ballots are recounted until one candidate receives a majority of the votes cast in a single round.

RCV elections have been found to have several benefits, from incentivizing less negative and more civil campaign environments (Donovan, Tolbert, \& Gracey, 2016), to increasing mobilization efforts (Bowler, Donovan, \& Brockington, 2003) and levels of voter satisfaction (Donovan et al., 2016; Farrell \& McAllister, 2006). Research also suggest RCV elections increase the likelihood of the winner being the most preferred or less extreme candidate (Grofman \& Feld, 2004; Horowitz, 2000). At the same time, however, some scholars argue that having to rank multiple candidates may be more cognitively and time demanding than simple, single-choice plurality elections, potentially resulting in increased rates of voters incorrectly filling out their ballot (e.g., Burnett \& Kogan, 2014; Neely \& Cook, 2008; Sinclair \& Alvarez, 2004) or abstaining altogether (e.g., McDaniel, 2016). Further, because of the uneven distribution of political resources and knowledge in the electorate across demographic groups (e.g., Delli Carpini \& Keeter, 1996; Verba, Schlozman, \& Brady, 1995), scholars often assume that different patterns in under-/over-voting arise from difficulties in voting in RCV elections (Neely \& Cook, 2008; Sinclair \& Alvarez, 2004). Yet, most studies regarding under-/over-voting rely on inferences from aggregate data (e.g., Burnett \& Kogan, 2014; Neely \& Cook, 2008), and none have directly tested the link between demographic groups, ranking difficulty, and tendencies to under-vote using individual level data. Few published studies have even directly measured which demographic groups find RCV voting challenging (e.g., Donovan et al., 2019; Kimball \& Kropf, 2016).

This study seeks to answer three interrelated questions: 1) Which voters find it difficult to rank candidates in RCV elections?; 2) Who is most likely to cast an undervoted ballot (not ranking all candidates)?; 3 ) Is there a relationship between finding RCV voting difficult and the likelihood of casting an under-voted ballot? Using a 1,000 people, nationally representative sample of likely 2020 Democratic primary voters, this study finds that $80 \%$ of respondents had no difficulty ranking candidates, with $51 \%$ saying the method was very easy. However, nearly $1 / 5$ of respondents said ranking candidates was somewhat or very hard, with more difficulty ranking linked to older age, lower political interest, and possibly more conservative ideologies. Additional analyses find that differences are most pronounced regarding the extent to which voters found ranking to be easy, not difficult.

Just about $12 \%$ of respondents asked to rank a hypothetical ballot of 2020 primary candidates under-voted. Surprisingly, despite their increased difficulty ranking candidates, older respondents were actually less likely to under-vote than were younger individuals. This relationship remains even after controlling for difficulty ranking, which does little to affect the relationship between age and under-voting. No significant relationships regarding under-voting were uncovered comparing racial and ethnic groups and only weak evidence linking socioeconomic status to under-voting. This suggests under-voting may be a choice, not the result of difficulty in casting a ballot.

These findings support earlier studies finding old voters face more challenges ranking candidates (Donovan et al., 2019) and lower under-vote rates (Neely \& Cook, 2008), as well as provide some evidence that ranking difficulty contributes to the tendency to cast incomplete ballots (Burnett \& Kogan, 2014). At the same time, they challenge those who suggest RCV disadvantages racial and ethnic minorities (e.g., McDaniel, 2016), women (e.g., Sinclair \& Alvarez, 2004), or those of lower socioeconomic status (e.g., Neely \& Cook, 2008).

The remainder of this article is as follows. The next section outlines the literature related to RCV's effects on difficulty voting and how that translates into undervoted ballots. It is in this section that hypotheses are formulated. Following this, the article estimates and analyzes how difficult RCV ranking is and who finds it difficult. The rate at which under-voted ballots were cast is then examined, focusing on who is more likely to cast them and the role ranking difficulty plays in casting undervoted ballots. The article then closes with a summary of the findings and suggestions for future work.

\section{Ranked-Choice Voting}

This once popular progressive-era reform has seen a resurgence in support as of late (Amy, 1996; Fortin, 2020; Santucci, 2017). In 2008, five US cities used RCV for local elections. As of the 2018 midterm election, 15 cities and the state of Maine had incorporated RCV into their election systems. In 2020, four states went so far as to use RCV for determining the winner of their respective Democratic primaries. That same year, ballot measures in Alaska and Massachusetts proposed statewide use of RCV for state and federal elections, passing in Alaska but failing in Massachusetts. Beginning in 2021, the largest city in the US, New York City, will start using RCV for all city primary and special elections. According to FairVote (2020), there have been nearly 400 RCV elections in the US since 2004 and over 10 million adults live in jurisdictions that use or recently implemented RCV for some elections. Given growing popularity of RCV in the US, it is becoming more imperative that scholars and policy makers understand the consequences of replacing plurality or majority systems with preferential voting.

On the one hand, previous literature has documented the positive effects of RCV elections on campaigns and voters. Because elections can be decided based on a voter's second, third, or subsequent choices, candidates in RCV elections have an incentive to behave more civilly or risk offending other candidates' bases and losing prospective second and third place rankings. This incentive to campaign civilly has led candidates in RCV 
elections to behave less negatively. Using text analysis, McGinn (2020) finds that candidates use less negative wording in their speeches when campaigning in RCV elections compared to those in plurality systems. RCV elections may be more civil, as voters in preferential election jurisdictions are more likely to perceive campaigns as less negative, perceive less candidate-to-candidate criticism, and be more satisfied with the campaigns than are those living in cities using plurality elections (Donovan et al., 2016).

It is not enough to just not offend your opponent's supporters; candidates must actively try to court them. This need to expand your base past core/likely supporters results in increased mobilization efforts in RCV elections (Bowler et al., 2003), though with mixed evidence of increased turnout effects (Kimball \& Anthony, 2016; McDaniel, 2016; McGinn, 2020). RCV elections have also been found to be more likely to result in the most preferred candidate being named the winner (Grofman \& Feld, 2004; Horowitz, 2000).

Notwithstanding the potential benefits of RCV, some scholars have also uncovered negative effects, primarily stemming from RCV's arguably increased difficulty compared to plurality or non-instant runoff methods. In non-preferential elections, voters only mark a single candidate. In preferential elections like RCV, voters are asked to rank several. Not only must voters possess knowledge about more candidates, but they must also be able to navigate more complex RCV ballots. Ranking multiple candidates using more complex ballots, especially in local or primary elections with less informational cues, may be taxing for American voters (Lau \& Redlawsk, 2006), potentially resulting in voters not ranking enough candidates (under-voting) or ranking too many (over-voting).

One of the few studies to directly measure voters understanding of different election systems in the US indicates RCV elections may be more difficult than plurality elections, but not by large margins. Donovan et al. (2019) find that $87 \%$ of voters thought RCV elections were somewhat or very easy, significantly but only slightly lower than in plurality cities (93\%). Other studies document similarly high rates of RCV comprehension or voting ease (Brischetto \& Engstrom, 1997; Cole, Taebel, \& Engstrom, 1990; Kimball \& Kropf, 2016). However, there is some evidence to suggest that issues with voting may differ by demographic group. Donovan et al. (2019) find that older individuals are more likely to report difficulty voting but did not find differences based on gender or race/ethnicity. In contrast, Neely, Blash, and Cook (2006) find that African American and Latino individuals reported lower understanding of RCV instructions (but see Kimball \& Kropf, 2016; Neely, Blash \& Cook, 2006).

Ballot complexity or difficulty ranking candidates has been assumed to be the cause of voters incorrectly filling out their ballots by either not marking enough candidates (under-voting) or marking too many (over-voting). Looking at rates of under-voting in four San Francisco elections where voters could rank up to three candidates, Burnett and Kogan (2014) find that $27 \%-48 \%$ of ballots cast did not have three unique candidates marked (i.e., under-voted), with $5 \%-12 \%$ of ballots having incorrectly marked the same candidate more than once (see also Neely \& McDaniel, 2015). The authors remark: "This likely reflects, at least in part, the reality that few voters possess enough information to rank more than a few of the candidates running, regardless of how many they are allowed to select" (Burnett \& Kogan, 2014, p. 48). Citing differences in political knowledge between men and women, Sinclair and Alvarez (2004) find that Los Angeles precincts with greater proportions of women see more under- and over-votes. Again, drawing on a case study of San Francisco, Neely and Cook (2008) and Neely and McDaniel (2015) find more erroneous ballots in neighborhoods that were disproportionality older, arguing difficulties that come with old age hinder properly filling out the ballot. Neely and Cook (2008) also find that precincts with larger Black and Latino populations had greater rates of over-votes (i.e., more ballots cast with too many candidates) and lower rates of under-votes (i.e., fewer ballots cast that did not rank all options); though, some evidence suggests differences in racial and ethnic voting may be partially attributable to different election technologies (e.g., Knack \& Kropf, 2003; Tomz \& Van Houweling, 2003).

These studies have made significant advances in documenting the effects of RCV elections; however, there still exist gaps in the literature regarding RCV difficulty, under-/over-voting, and demographic disparities. First, most previous studies focus on one or a handful of election jurisdictions. As such, scholars know less about voting in RCV elections on a national scale. Second, more evidence and individual level data (as opposed to aggregate election results) is needed to link RCV difficulty to particular demographic groups. Few studies have documented significant differences in RCV difficulty among different demographic groups (e.g., Donovan et al., 2019; Kimball \& Kropf, 2016) and none have directly linked increased difficulty ranking choices with an increased likelihood of under- or over-voting. Previous studies often rely on aggregate data to make inferences about individual voting behavior, assuming that the relationship between greater proportions of some demographic in a precinct being correlated with more under-/overvotes reflects increased difficulty voting among that demographic. Ecological fallacies and other issues suggest there is reason to believe under-votes are not cast out of ignorance or difficulty.

Though under-voting is often attributed to voter fatigue (Bullock \& Dunn, 1996), ballot confusion (Kimball \& Kropf, 2005), or voter ignorance (Wattenberg, McAllister, \& Salvanto, 2000), under-voting can also reflect the true preferences of the voter, not any difficulties they may have encountered. For example, Alvarez, Hall, and Levin, (2018) find that under-voting rates were nearly identical between partisan RCV elections and 
non-partisan ones. If RCV makes voting harder, then removing party labels should exacerbate that difficulty. The finding that voters were nearly as likely to undervote with or without labels suggests that under-voting may not be as strongly tied to ranking difficulty as past scholars have assumed.

This study seeks to expand on previous works by examining whether and which voters find RCV elections difficult, who is likely to cast an under-voted ballot, and whether RCV difficulty contributes to the likelihood of casting such a ballot. In doing so, this study tests the often-made assumption that certain groups experience greater difficulty in RCV elections, and these difficulty disparities lead to greater rates of erroneous ballots.

Building on previous work, this study tests the following hypotheses:

H1: RCV difficulty and demographic hypotheses: Older, Black, Hispanic, and female respondents will have greater difficulty using RCV.

H2: RCV exhausted ballot hypothesis: Those who have greater difficulty with RCV will be more likely to cast under-voted ballots.

H3: RCV difficulty and demographic hypotheses: Older, Black, Hispanic, and female voters will be more likely to cast under-voted ballots.

\section{Data}

Data for this study are from a 1,000 people, nationally representative Internet survey of likely Democratic primary voters conducted approximately three months before primary elections began (November 2019). The survey was administered by YouGov, an internationally recognized survey firm that has frequently conducted political surveys (e.g., the Cooperative Congressional Election Studies). YouGov recruits respondents through their online, opt-in survey process that pays respondents for their time. The purpose of the study was to gauge likely Democratic primary voters' candidate preferences, their respective rankings, and their views on RCV. As such, the survey screened out respondents who were unlikely to vote in the primaries and any respondents who did not identify as Democrat or Independent. Census data is used to weight respondents so they represent the national electorate. Summary statistics for all variables used in this study can be found in Table A1 in Supplementary File A.

Two specific questions were asked in the survey. The first asks: "Imagine that the Democratic primary election were held in your state today and the candidates were only [randomized: Joe Biden, Pete Buttigieg, Kamala Harris, Bernie Sanders, and Elizabeth Warren]. How would you rank these candidates? Please drag your 1st-choice candidate into the box labeled Number 1, your 2nd choice in the box labeled Number 2, and so on" (see Table 3). The respondents were then presented with a randomized list of candidates where they would click and drag the candidate names to different rankings. This question is used to explore the rates of under-voting with RCV. The second question immediately follows: "How hard or easy was it to rank more than one choice in the previous question?" with responses from very easy to rank more than one choice, somewhat easy, neither hard nor easy, somewhat hard, and very hard to rank more than one choice (see Table 1). This question is used to measure how difficult respondents found ranking to be, coded so that 1 represents those answering very easy, to 5 for those answering very difficult.

This data provides several advantages to studying RCV. First, respondents were asked to rank the 2020 Democratic candidates in what was essentially an online RCV ballot, then immediately asked how difficult they found the process. As such, this study measures how difficult respondents found the actual process of ranking candidate using an RCV ballot, not more general questions about whether voters understood the system in their area (e.g., Donovan et al., 2019). Second, using RCV in federal general elections would usually involve ranking partisan/ideologically opposed candidates, presenting clearer options through the use of shortcuts (Lau \& Redlawsk, 2006). Ranking candidates without partisan labels effectively renders partisanship a non-heuristic, as respondents cannot use partisan labels to differentiate candidates. Investigating difficulties with ranking more ideologically similar candidates with the same party provides a more restrictive test as partisan cues are absent.

At the same time, using this data has some limitations. First, likely primary voters vary from the general electorate in that they tend to be more interested, knowledgeable, and more partisan (Karpowitz \& Pope, 2015; Redlawsk, Bowen, \& Tolbert, 2008; see also Abramowitz, 2008). Second, the analyses only pertain to Democratic primary voters (i.e., no Republicans). Thus, while the results reported here are theoretically interesting, it is worth considering the extent to which the relationships uncovered can be generalized to the US population.

\section{Difficulty of Ranked-Choice Voting}

Table 1 displays the difficulty of ranking candidates, where voters were asked how hard or easy it was to rank more than one choice, with options ranging from very easy (1) to very hard (5). $68 \%$ of respondents said ranking candidates was easy or very easy, with nearly $2 / 3$ of those citing 'very easy.' In contrast, just under $20 \%$ found ranking to be hard or very hard, with only $1 / 3$ citing ranking difficult as very hard. The remaining $12 \%$ of respondents found ranking neither hard nor easy. Including those who said neither hard nor easy with the $68 \%$ that reported ranking as very/somewhat easy suggests $80 \%$ of respondents found RCV to not be difficult to use, comparable to previous studies (Donovan et al., 2019; Kimball \& Kropf, 2016). 
Table 1. Difficulty ranking candidates.

\begin{tabular}{lrr}
\hline Difficulty ranking candidates & No. & $\%$ \\
\hline Very easy to rank more than one choice & 412 & 41.2 \\
Somewhat easy to rank more than one choice & 272 & 27.2 \\
Neither hard nor easy to rank more than one choice & 119 & 11.9 \\
Somewhat hard to rank more than one choice & 132 & 13.2 \\
Very hard to rank more than one choice & 65 & 6.5 \\
Total & 1,000 & 100.0 \\
\hline
\end{tabular}

To examine the extent to which difficulty differs by demographic or political characteristics, Table 2 reports an ordered logistic regression model where the dependent variable is how difficult respondents found ranking candidates ( $1=$ very easy, $5=$ very hard). This study includes a continuous measure of Age (19-88), a variable denoting whether the respondent is a Female ( 1 = Female, 0 = Male); two variables for race, whether the respondent is Black ( $1=$ Black, non-Hispanic, $0=$ Not Black) or is another race besides white, non-Hispanic (Other: 1 = Other race, $0=$ Not another race). White, non-Hispanic respondents are the reference (left out) group. Also included are two measures of socioeconomic status: Income $(1=$ Less than $\$ 10,000,16=$ Greater than $\$ 500,000)$ and Education (1 = High School graduate or less, 5 = Post-Graduate Degree). A variable denotes whether the respondent identifies as a Moderate Democrat ( $1=$ Moderate Democrat, $0=$ other) or Strong Democrat ( 1 = Strong Democrat, $0=$ other $)$ is included to control for partisan strength. Being as the sample only includes Democrats and Independents, the reference category consists of Independent-identifying respondents. A measure of Liberalism ( 1 = Conservative, $4=$ Very Liberal) is included, as is a measure of Political Interest ( 1 = High Interest, 0 = Low Interest) and Importance of Religion ( 1 = Not at all important, $4=$ Very important). Though almost every variable had $100 \%$ response rates, responses for Income, Ideology (Liberalism), and Political Interest dipped just slightly $(89.4 \%, 96.2 \%$, and $99.4 \%$, respectively). The reported analyses code missing to the respective mean or median values to maintain statistical precision. Results are robust their exclusion unless otherwise noted (see Tables C3 and C4 in Supplementary File C). A breakdown of each variable by what percentage answered different rankings of RCV difficulty can be found in Table D1 in Supplementary File D. Lastly, to deal with heterogeneity and spatial dependence, the estimations are computed with robust standard errors clustered by state, but results are robust to the inclusion of state fixed effects (available at request).

Preliminary model checks indicated that the assumption of parallel odds may be violated. Analyses were reestimated using multinomial regression and the only difference of note being female respondents report greater difficulty. However, this finding may not be unique to RCV elections and may also be evident in plurality elections (Donovan et al., 2019). Given results are nearly identi- cal and that ordered logistic regression models are more straightforward, this study reports the ordered logistic model in the main text and the multinomial estimation in Table C1 of Supplementary File C. Results are also robust to collapsing the dependent variable into a three categorical variable of very/somewhat easy, neither, and very/somewhat hard, regardless of estimation strategy (see Table C2 and C7 in Supplementary File C). As an additional robustness check, Model 1 is re-estimated using ordinary least square regression and is presented in column 2 of Table 2 . These results are also robust to separating the models in Table 2 and 3 so that each estimation strategy has one model with only socio-demographic factors followed by a second with socio-demographic and political factors. Results reported in Tables C5-C6 in Supplementary File $\mathrm{C}$ to save space. For interpretability of the ordered logistic coefficients and comparability to the ordinary least squares model, both models in Table 2 report odd-ratios, where ratios greater than one suggest greater odds of encountering difficulty (positive relationship) and those below one suggest lower odds (negative relationship). The values reported in Table 2 are odd-ratios, not unstandardized regression coefficients.

As can be seen in Table 2, there does exist some differences in who perceives RCV and ranking to be more or less difficult. In both models, older, less politically interested, and more ideologically conservative respondents are more likely to report greater difficulty voting, with similar odds-ratios across models.

To more clearly depict the relationships at hand, Figures 1 and 2 plot the predicted probability of answering ranking was very easy, easy, neither, hard, or very hard across these demographic and political characteristics. Figure 1 show older respondents are more likely to report difficulties ranking, in line with previous work (Donovan et al., 2019) and supporting the assumption that increased difficulty may cause greater voting errors in older communities (e.g., Neely \& Cook, 2008; Neely \& McDaniel, 2015). Respondents one standard deviation above the mean (49 years) are $15 \%$ less likely to report ranking being very easy than those one standard deviation below the mean (44\% younger, $29 \%$ older). If the range is extended to two standard deviations above/below the mean, the youngest voters are nearly twice as likely to report ranking being very easy compared to the oldest ( $48 \%$ younger, $25 \%$ older). Younger and older respondents are no more or less likely to rank 
Table 2. Who finds ranking difficult? (Odd-ratios).

(1)

Ordered Logistic Regression $\mathrm{b} / \mathrm{se}$
(2)

Ordinary Least Squares Regression b/se

\begin{tabular}{lcc}
\hline main & $1.017^{* * *}$ & \\
Age & $(0.004)$ & $1.010^{* * *}$ \\
Female & 1.184 & $(0.003)$ \\
& $(0.159)$ & 1.120 \\
Black & 1.136 & $(0.099)$ \\
& $(0.270)$ & 1.122 \\
Hispanic & 1.004 & $(0.185)$ \\
& $(0.192)$ & 1.023 \\
Other & 1.429 & $(0.142)$ \\
& $(0.323)$ & 1.223 \\
Income & 1.020 & $(0.202)$ \\
& $(0.025)$ & 1.019 \\
Education & 0.991 & $(0.016)$ \\
& $(0.050)$ & 0.975 \\
Moderate Democrat & 1.138 & $(0.035)$ \\
& $(0.224)$ & 1.060 \\
Strong Democrat & 0.912 & $(0.153)$ \\
& $(0.124)$ & 0.912 \\
Liberalism & $0.795^{* *}$ & $(0.074)$ \\
& $(0.077)$ & $0.876^{*}$ \\
Political Interest & $0.577^{* * *}$ & $(0.059)$ \\
& $(0.055)$ & $0.709 * * *$ \\
Importance of Religion & 0.981 & $(0.044)$ \\
& $(0.067)$ & 0.994 \\
& & $(0.045)$
\end{tabular}

Observations

1,000

1,000

Notes: Coefficients converted into odds-ratios for comparability and interpretability. See Supplementary File C for models reporting coefficients. Both models estimated with robust and clustered(state) standard errors. ${ }^{*}=0.1 ; * *=0.05 ;^{* * *}=0.01$

voting as somewhat easy, while older voters are $5 \%$ more likely to report ranking as neither hard nor easy (10\% younger, $15 \%$ older). Looking at how difficult they find the process, older voters are also twice as likely to say that ranking candidates was somewhat difficult ( $10 \%$ younger, $20 \%$ older) or very difficult ( $4 \%$ younger, $10 \%$ older), further emphasizing the differences across age groups.

At the same time, these results show the largest differences among age do not reflect difference in how difficult respondents find ranking to be, but the extent to which they find it easy. The largest differences in Figure 1 occur when comparing whether voters find voting very easy, with smaller differences for other difficulties. Further, looking at the bottom right panel in Figure 1 , which predicts the level of difficulty ( $1=$ very easy, 5 = very hard) across a range of ages using ordinary least squares, the results suggest that young respondents tend to find ranking very/somewhat easy (1.63), while older respondent find ranking to be somewhat easy (2.22), with a difference of roughly .60 (just over half a ranking level). This finding suggests that, though there are differences in ranking difficulty, they may not be drastic. Yet, it is worth re-mentioning that this survey was conducted over the internet where respondents ranked candidates using an online survey tool where they dragged and dropped candidate names into boxes representing their preferences, a process different than filling in bubbles in standard RCV ballots. Given the relationship between age and computer literacy, future researchers should consider the extent to which survey format may be inducing this relationship.

Perhaps due to the linkage between political interest and knowledge (Delli Carpini \& Keeter, 1996), the most interested find RCV to be easier than the least interested (Figure 2). Those with high political interest are over ten percentage points more likely to find ranking very easy (24\% low interest, $36 \%$ high). Only small and potentially indistinguishable differences arise when comparing the likelihood of answering somewhat easy or not easy nor 

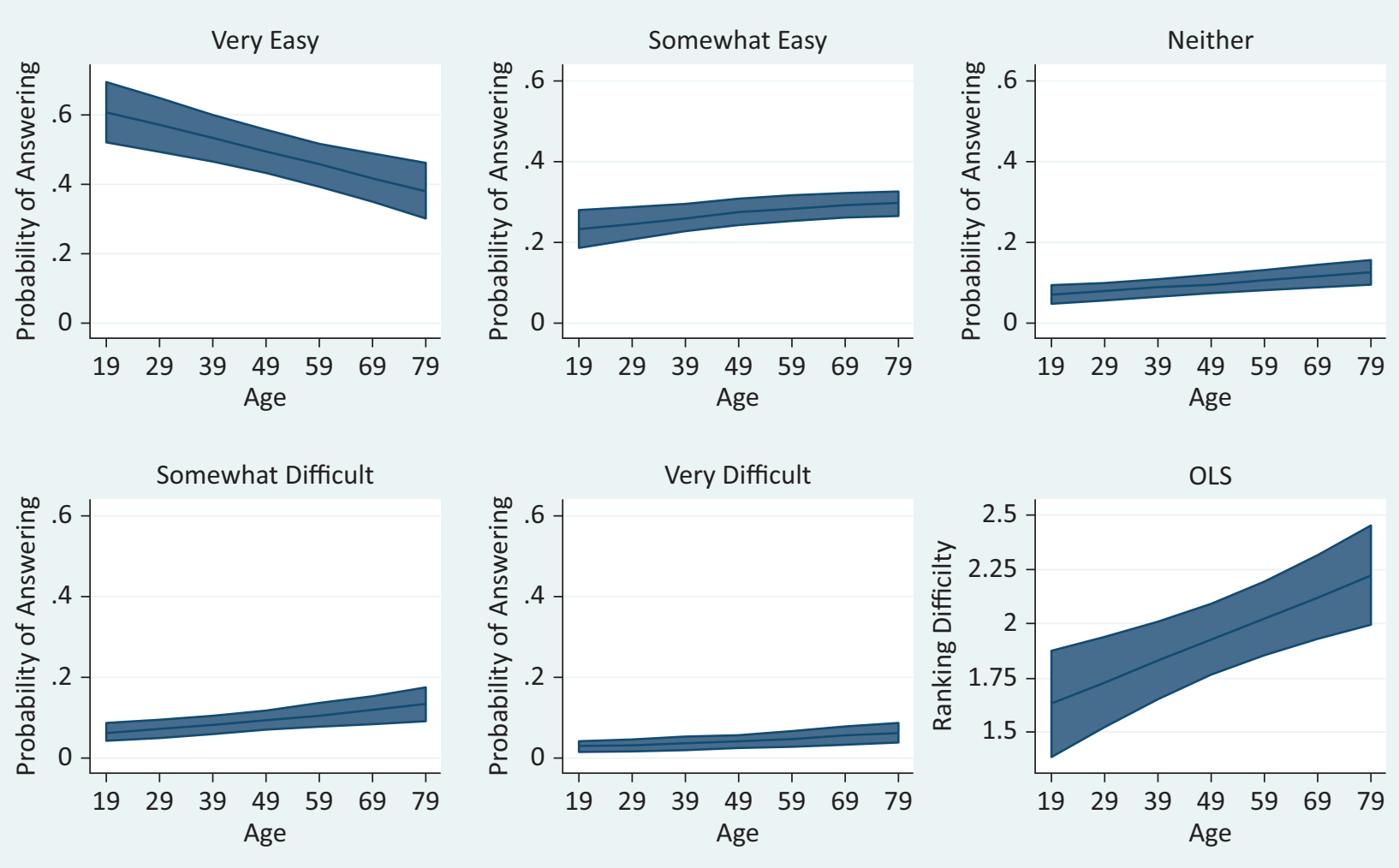

Figure 1. Effects of age in difficulty with ranking candidates. Notes: $N=1,000$. OLS = Ordinary Least Squares regression. All other panels derived from ordered logistic regression estimates. Estimation of all coefficients calculated with all other variables held at their mean or respective values. Robust and clustered(state) standard errors employed. Source: Author's survey using the YouGov platform, in November 2019.

hard. There is some evidence to suggest less interested individuals also find ranking more difficult. Less interested respondents are $6 \%$ more likely to say ranking was somewhat easy (14\% low interest, $20 \%$ high) and four percentage points more likely to say ranking was very difficult (7\% low interest, $11 \%$ high).

Again, the biggest differences arose regarding who is more likely to cite ranking as very easy, with only slight differences in who finds rankings somewhat easy, neither, or very difficult, and moderate differences in finding RCV to be somewhat hard. Looking at the ordinary least squares results in the bottom right panel, the least interested are estimated to report ranking as somewhat easy/neither her nor easy (2.37), while the more interested are predicted to say it is somewhat easy (1.92). Once again, these results suggest that different groups may find ranking more difficult, but the biggest differences may lie in the extent to which respondents view RCV as easy. With that being said, these findings may not be unique to RCV elections. Donovan et al. (2019) also find that those with greater interest report better understanding of RCV elections. However, as did those in plurality and two-top primary elections. The authors did not report any differences in the effects of interest across election environment.

Interestingly, even after controlling for a host of other influences, ideological differences in ranking dif- ficult are apparent (Figure D1 in Supplementary File D). Specifically, the most liberal respondents are $15 \%$ more likely to say ranking was very easy than were more conservative Democrats or Independents (41\% very liberal, $26 \%$ conservative). Liberal respondents are also less likely to rank voting as somewhat or very hard, and only slight differences were uncovered in ranking somewhat easy or neither. Using ordinary least squares regression, the least liberal respondents are predicted to report ranking be somewhat easy (2.19), while the most liberal are more likely to report ranking being very/somewhat easy (1.79). It could be that more conservative Democrats and Independents have less familiarity with the progressive reform of RCV. However, it is probably more likely that the lack of partisan heuristics among (mostly) Democratic candidates forced respondents to rely on other candidate information (e.g., candidate positions [Abrajano, Nagler, \& Alvarez, 2005]) when making their choices (Alvarez et al., 2018). Such information may be less readily available in the minds of more conservative respondents who may have less familiarity with the Democratic candidates. Again, the evidence presented here suggests the greatest differences occur when deciding whether ranking was very easy.

Taken together, these results challenge the assumption that higher rates of under-/over-voting among specific demographic groups (other than age) is attributable 

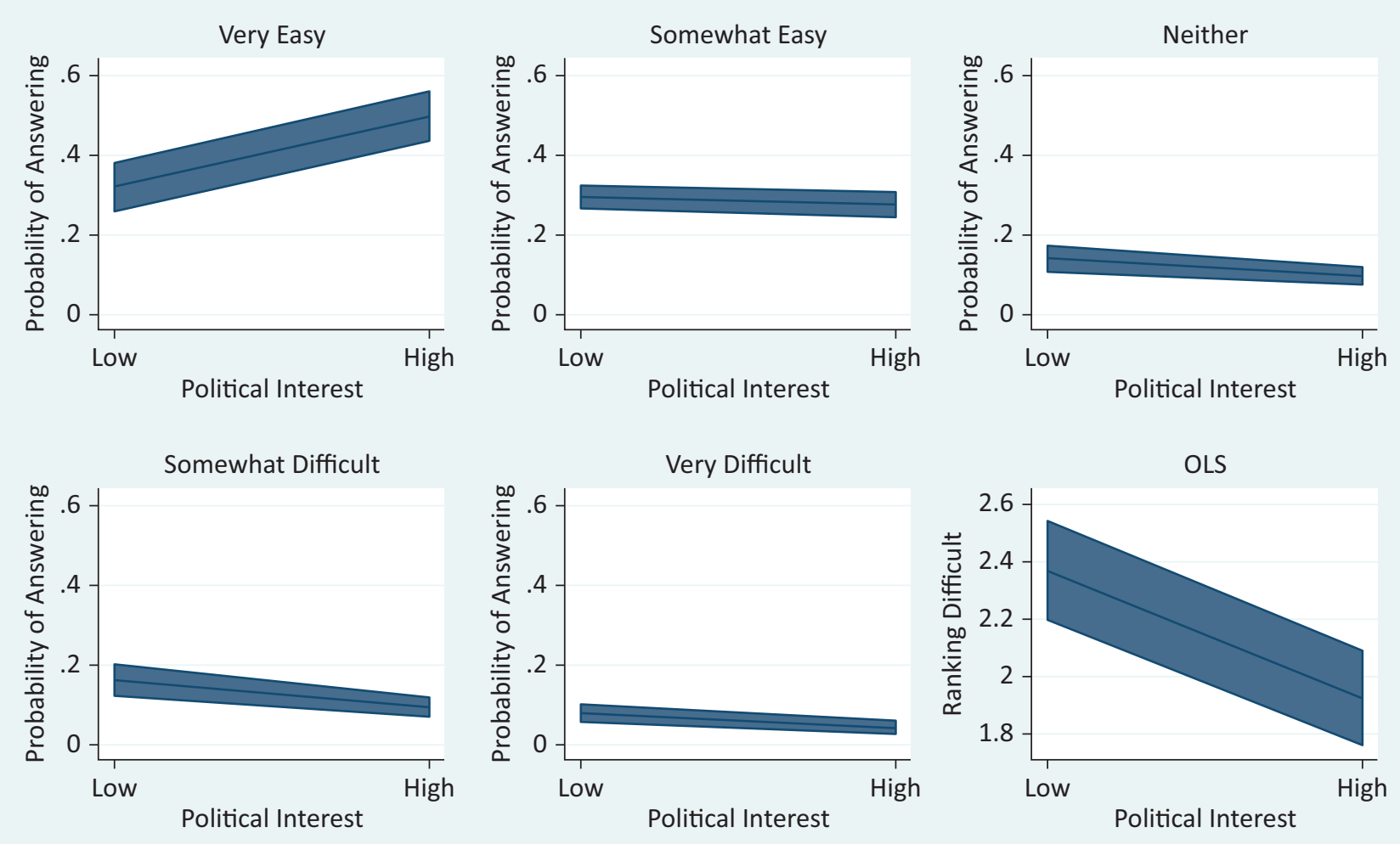

Figure 2. Effects of political interest on difficulty with ranking candidates. Notes: $N=1,000$. OLS = Ordinary Least Squares regression. All other panels derived from ordered logistic regression estimates. Estimation of all coefficients calculated with all other variables held at their mean or respective values. Robust and clustered(state) standard errors employed. Source: Author's survey using the YouGov platform, in November 2019.

to increased difficulty they face in RCV elections. To more fully understand who casts under-voted ballots and whether difficulty plays a role in casting such ballots, the next section examines under-votes in a (semi-)hypothetical Democratic primary race.

\section{Under-Voted Ballots}

Under-voted ballots occur when voters do not rank as many candidates as there are rankings available. Undervoting has been found to be undergirded by voter fatigue (Bullock \& Dunn, 1996), ballot confusion (Kimball \& Kropf, 2005), and voter ignorance (Wattenberg et al., 2000). However, a voter may also under-vote because they would rather not vote than have their vote cast for a unpreferred candidate.
To examine the extent of under-voting and the role RCV difficulty plays across demographic groups, this study uses rankings from a truncated five-candidate race of 2020 Democratic primary candidates. The survey asked respondents to rank the following candidates from first(one) to last(five): Joe Biden, Pete Buttigieg, Kamala Harris, Bernie Sanders, and Elizabeth Warren (see Data section or Supplementary File B for question wording). The ballot allows up to five candidates and there are five candidates in the race, meaning that if any voter did not rank all five candidates, their ballot is undervoted. Table 3 shows each candidate and the number of votes cast for them by order of preference, as well as the number who did not rank the candidate when given the option. Those that skipped a candidate are essentially creating under-voted ballots. Because voters can

Table 3. Candidate rankings.

\begin{tabular}{lccccc}
\hline Ranking & Joe Biden & Pete Buttigieg & Kamala Harris & Bernie Sanders & Elizabeth Warren \\
\hline 1 & 311 & 73 & 96 & 190 & 305 \\
2 & 166 & 103 & 189 & 224 & 273 \\
3 & 117 & 233 & 213 & 165 & 189 \\
4 & 149 & 241 & 252 & 129 & 119 \\
5 & 189 & 255 & 155 & 227 & 44 \\
Did not rank candidate & 52 & 79 & 79 & 49 & 54 \\
\hline
\end{tabular}


choose not to rank multiple candidates, the total number of exhaustible ballots is not simply the sum of all those who skipped. After removing double counts due to respondents skipping multiple candidates, the total number of ballots cast that did not fill all ranking options is 117 , or $12 \%$ of the votes cast in the election-a rate similar to those found by Burnett and Kogan (2014) when voters only had to rank three candidates.

To determine who is more likely to cast under-voted ballots and whether difficulty ranking plays a key role, Table 4 displays two standard logistic regression results using the same model specification (covariates) as discussed above. Results are robust to alternative specifications except those relating to income and gender when omitting those who did not answer income or liberalism (see Supplementary File C). Model 1 regresses whether someone cast an under-voted ballot on a host of demographic and political variables. Model 2 repeats this pro- cess but includes how difficult the respondent found ranking to be to see if difficulty ranking mediates any relationships found in Model 1. Though not a perfect estimation strategy, if a coefficient is significant in Model 1 , but not Model 2, this may suggest that systematic differences in difficulty ranking candidates may be influencing the relationship. Though, results are robust to the use of alternative mediating strategies, such as the causal step approach of Baron and Kenny (1986) or the non-parametric approach devised by Imai, Keele, Tingley, and Yamamoto (2011), available at request. Again, oddsratios are reported in the table to allow for better comparison across models and covariates. Odds ratios above 1 denote a positive relationship (greater undervoting likelihood) and below 1 a negative relationship (lower under-voting likelihood).

Who is more likely to under-vote? Contrary to expectations given the results uncovered in the previous

Table 4. Who under-votes? (Odds-ratios).

\begin{tabular}{|c|c|c|}
\hline & $\begin{array}{c}\text { (1) } \\
\text { Without Difficulty } \\
\text { b/se }\end{array}$ & $\begin{array}{c}(2) \\
\text { With Difficulty } \\
\text { b/se }\end{array}$ \\
\hline Under-voted difficulty ranking candidates & & $\begin{array}{l}1.543^{* * *} \\
(0.115)\end{array}$ \\
\hline Age & $\begin{array}{l}0.986 * * \\
(0.006)\end{array}$ & $\begin{array}{l}0.980 * * * \\
(0.007)\end{array}$ \\
\hline Female & $\begin{array}{c}1.380 * \\
(0.261)\end{array}$ & $\begin{array}{c}1.313 \\
(0.237)\end{array}$ \\
\hline Black & $\begin{array}{c}0.751 \\
(0.250)\end{array}$ & $\begin{array}{c}0.690 \\
(0.224)\end{array}$ \\
\hline Hispanic & $\begin{array}{c}0.754 \\
(0.206)\end{array}$ & $\begin{array}{c}0.782 \\
(0.210)\end{array}$ \\
\hline Other & $\begin{array}{c}1.133 \\
(0.350)\end{array}$ & $\begin{array}{c}1.053 \\
(0.313)\end{array}$ \\
\hline Income & $\begin{array}{l}1.065^{* *} \\
(0.029)\end{array}$ & $\begin{array}{l}1.057^{* *} \\
(0.029)\end{array}$ \\
\hline Education & $\begin{array}{c}0.919 \\
(0.085)\end{array}$ & $\begin{array}{c}0.936 \\
(0.087)\end{array}$ \\
\hline Moderate Democrat & $\begin{array}{c}1.760 * \\
(0.530)\end{array}$ & $\begin{array}{c}1.773^{*} \\
(0.559)\end{array}$ \\
\hline Strong Democrat & $\begin{array}{c}1.041 \\
(0.279)\end{array}$ & $\begin{array}{c}1.108 \\
(0.290)\end{array}$ \\
\hline Liberalism & $\begin{array}{c}0.830 \\
(0.120)\end{array}$ & $\begin{array}{c}0.861 \\
(0.134)\end{array}$ \\
\hline Political Interest & $\begin{array}{l}0.719 * * * \\
(0.091)\end{array}$ & $\begin{array}{c}0.820 \\
(0.102)\end{array}$ \\
\hline Importance of Religion & $\begin{array}{c}1.057 \\
(0.143)\end{array}$ & $\begin{array}{c}1.055 \\
(0.138)\end{array}$ \\
\hline Observations & 1,000 & 1,000 \\
\hline
\end{tabular}

Notes: Under-voting occurs when a respondent did not rank all candidate options available on the survey ballot. Logistic regression estimated with robust and clustered(state) standard errors. Odds-ratios shown for comparability across models. ${ }^{*}=0.1 ;{ }^{* *}=0.05$; $* * *=0.01$ 
section, Model 1 suggests that older individuals are less likely to under-vote, in line with previous work (Neely \& Cook, 2008). Additionally, Model 1 suggests that more interested individuals are less likely to under-vote, while female (see also, Neely \& Cook, 2008; Sinclair \& Alvarez, 2004), more affluent and moderate partisans are more likely to not rank all the candidates. Moderate partisans may under-vote out of dislike for one of the more liberal candidates running in the election, not because of cognitive difficulties ranking. Additionally, it should be noted that gender, political interest, and income fail to reach statistical significance in several alternative specifications using multinominal regression (see Supplementary File C).

The left panel of Figure 3 plots the predicted probability of not ranking all candidates across different values of age (without controlling for ranking difficulty). As can be seen, older respondents are $11 \%$ less likely to cast an under-voted ballot than are the youngest voters (21\% younger, $10 \%$ older), in line with aggregate analyses that have found lower under-vote rates in older precincts (e.g., Neely \& Cook, 2018). Further, this relationship holds when controlling for difficulty (Model 2, right panel in Figure 3) and doing so only slightly affects the substantive relationship between age and casting under-votes (20\% younger, $7 \%$ older). The evidence that controlling for difficulty has little effect on the relationship suggests that difficulty is not what is causing younger voters to not rank all candidates. Instead, it could be abstention related to candidate preferences (e.g., 'Bernie or Bust').
Considering the other significant findings, female respondents are $4 \%$ more likely to under-vote than male respondents ( $11 \%$ male, $15 \%$ female). This finding is eliminated after controlling for difficulty. More interested individuals are $4 \%$ less likely to under-vote (19\% low interest, $15 \%$ high), while more affluent individuals are $6 \%$ more likely to under-vote, and moderate democrats are $7 \%$ more likely. The results for income and moderate democrat remain after controlling for difficulty ranking, while those for gender and interest are rendered insignificant. Considering these results, more interested individuals, as well as moderate Democrats, are unlikely to suffer from a lack of political knowledge regarding the 2020 Democratic candidates, leading to lower undervote rates. Rather, it is likely a choice not to rank all the candidates. Finally, more affluent individuals may simply possess greater resources or a greater 'stake in the game' given the emphasis on taxing the rich among the 2020 Democratic primary candidates, leading to a choice to under-vote.

An important finding is that difficulty ranking is strongly linked to casting under-voted ballots (Model 2). Those who had the greatest difficulty ranking are nearly four times as likely to not fill out all rankings than were those who faced the least difficulty (Figure 4). Specifically, the likelihood of under-voting a ballot increases from $8 \%$ for those who had the least difficulty to, to $18 \%$ for those who found ranking neither hard nor easy, to nearly $34 \%$ for those who experienced the most difficulty. These results suggest that, for the $20 \%$ of the
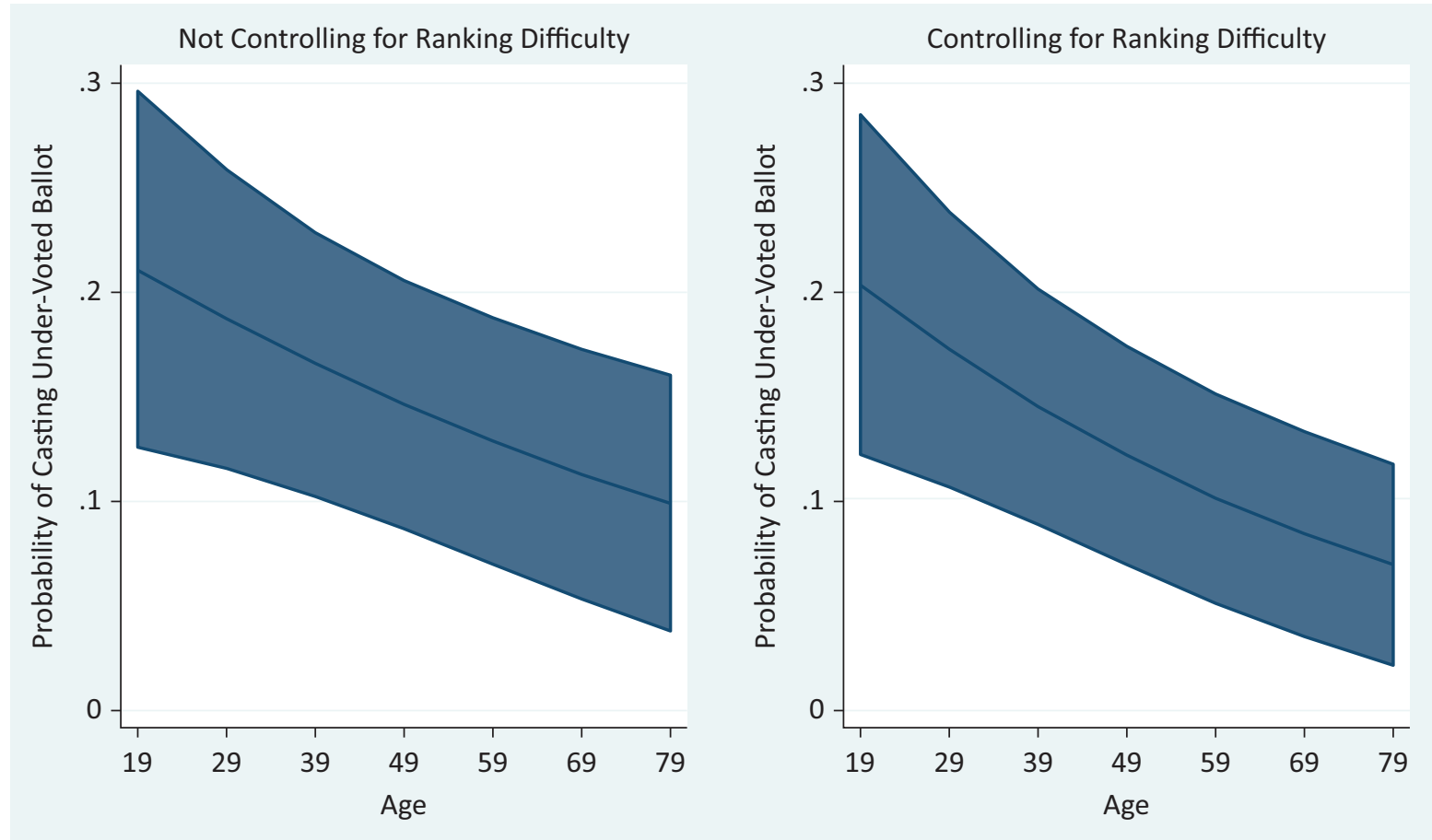

Figure 3. Effects of age on casting an under-voted ballot. Notes: $N=1,000$. Under-voted ballots occur when a voter does not select a candidate for each ranking available. Estimation of logistic regression coefficients calculated with all other variables held at their mean or respective values. Robust and clustered(state) standard errors employed. Source: Author's survey using the YouGov platform, in November 2019. 


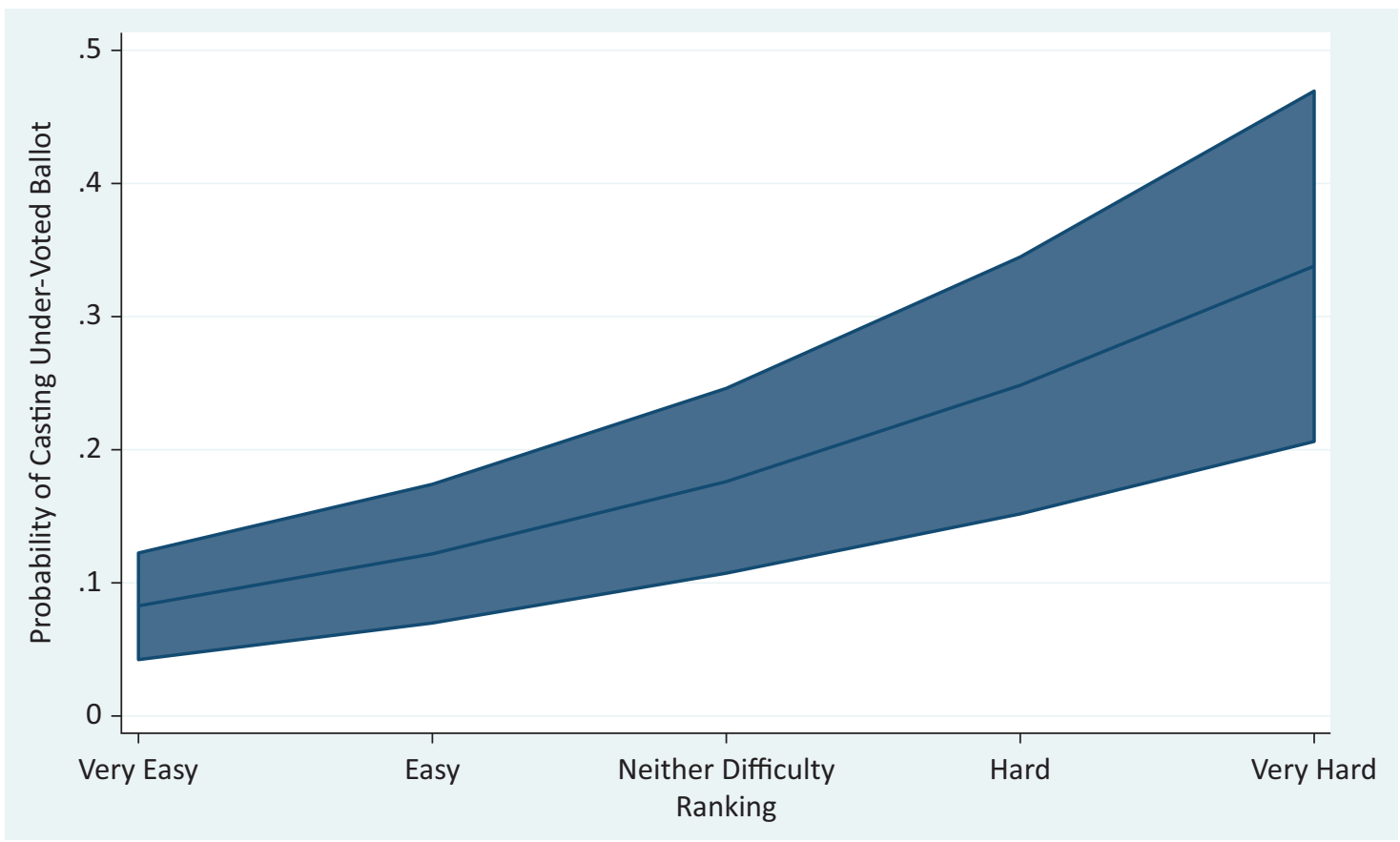

Figure 4. Effect of difficulty ranking candidates on casting an under-voted ballot. Notes: $N=1,000$. Under-voted ballots occur when a voter does not select a candidate for each ranking available. Estimation of logistic regression coefficients calculated with all other variables held at their mean or respective values. Robust and clustered(state) standard errors employed. Source: Author's survey using the YouGov platform, in November 2019.

sample who had difficulty ranking candidates, that difficulty may have been a serious impediment potentially resulting in greater likelihood of not ranking all candidate options. Though not as stinging a rebuke as Burnett and Kogan (2014, p. 48), these results provide support for the assumption that high under-voting rates may be linked to greater difficulty ranking candidates.

\section{Summary and Conclusion}

This study tests the assumptions that certain demographic groups experience greater difficulty with RCV, that under-voting is a result of voters experiencing greater difficulty, and that patterns of under-voting reflect differences in how difficult voters find RCV to be across demographic groups. Using a nationally representative sample of likely Democratic primary voters (YouGov, $N=1,000$ ), this article finds that a large majority of respondents found ranking to be easy. Greater difficulty ranking was found among older voters (also see Donovan et al., 2019), with some additional evidence that the less interested and more conservative may have also encountered greater difficulty. Where differences in difficulty were uncovered, evidence suggests they reflect differences in the extent to which voters found RCV to be easy, not hard, further suggesting that most voters find RCV easy. Additionally, little to no evidence of differences in difficulty were found among racial, ethnic, or socioeconomic groups, contrary to arguments made elsewhere.

Looking at under-voting (when a voter does not fill out all the rankings provided), this study finds that only
$12 \%$ of voters under-voted, a rate similar to those uncovered in a previous study using ballots cast in an actual election (Burnett \& Kogan, 2014). Contrary to expectations, the results show only mixed evidence of socioeconomic factors influencing under-voting, and no evidence of racial or ethnic differences. Only age and difficulty ranking candidates are significant predictors of undervoting across all model specifications, with younger respondents and those who experience greater difficulty being more likely to under-vote. Though younger voters were found to be more likely to under-vote, the lack of greater difficulty ranking for young people coupled with the inability of RCV difficulty to affect this relationship suggests youth under-voting may be caused by something other than the ranking process.

Taken together, these findings challenge the assumption that difficulty with RCV differs by demographic group (other than age) and that these differences in difficulty are the cause of different under-voting rates. Instead, the results suggest that difficulty is a contributing factor to under-voting but does not unduly burden voters based on most demographic characteristics, and that, for many voters, under-voting may be a choice. Still, questions remain, and future studies should consider exploring more thoroughly the relationships uncovered here.

First, a strength and limitation of this study is that the respondents are only likely Democratic primary voters. On the one hand, this provides a stronger test of the degree of difficulty voters find RCV to be by forcing them to rank candidates in an election without the use 
of party labels as a heuristic. On the other hand, likely Democratic primary voters are unlikely to be representative of the average voter, limiting the generalizability of the study. Future works should consider ways to expand this study to the general electorate. Second, future studies should distinguish reasons for increased difficulty. It is likely less interested and more conservative individuals faced greater difficulty due to less knowledge regarding the many Democratic candidates. For older individuals, did age-related ailments make navigating the ballot more difficult or was something else at play? It is worth noting that additional analyses were conducted using generational cutoffs to predict ranking difficulty (available upon request). Some significant differences were uncovered depending on model specification, with the youngest generations seeing less difficulty, little differences uncovered for those in the middle, and the oldest generation seeing increased difficulty. Third, future studies should examine why the individual-level under-voting results reported here differ from aggregate results uncovered elsewhere. For example, this study finds no relationship between racial and ethnic minorities and under-voting and a positive relationship (greater under-voting) among richer respondents. At the same time, other work has found lower under-voting rates for precincts with greater proportions of non-white voters and lower under-voting rates in precincts with higher median income (e.g., Neely \& Cook, 2008). Is it something about the area under study (i.e., usually San Francisco, CA), or perhaps these differences are accounted for by differences in voting technology across jurisdictions (e.g., Knack \& Kropf, 2003)?

\section{Acknowledgments}

The author would like to thank Scott LaCombe for reviewing an earlier draft of this work. The author would also like to thank the editors and reviewers for their constructive feedback.

\section{Conflict of Interests}

The author declares no conflict of interests.

\section{Supplementary Material}

Supplementary material for this article is available online in the format provided by the author (unedited).

\section{References}

Abrajano, M. A., Nagler, J., \& Alvarez, R. M. (2005). Racebased versus issue based voting: A natural experiment: The 2001 city of Los Angeles elections. Political Research Quarterly, 58(2), 203-218.

Abramowitz, A. (2008). Don't blame primary voters for polarization. The Forum, 5(4).

Alvarez, R. M., Hall, T. E., \& Levin, I. (2018). Low- information voting: Evidence from instant-runoff elections. American Politics Research, 46(6), 1012-1038.

Amy, D. J. (1996). The forgotten history of the single transferable vote in the united states. Representation, 34(1), 13-20.

Baron, R. M., \& Kenny, D. A. (1986). The moderatormediator variable distinction in social psychological research: Conceptual, strategic, and statistical considerations. Journal of Personality and Social Psychology, 51(6). https://doi.org/10.1037//0022-3514.51. 6.1173

Bowler, S., Donovan, T., \& Brockington, D. (2003). Electoral reform and minority representation: Local experiments with alternative elections. Columbus, $\mathrm{OH}$ : Ohio State University Press.

Brischetto, R. R., \& Engstrom, R. L. (1997). Cumulative voting and Latino representation: Exit surveys in fifteen Texas communities. Social Science Quarterly, 78(4), 973-991.

Bullock, C. S., III, \& Dunn, R. E. (1996). Election roll-off: A test of three explanations. Urban Affairs Review, 32(1), 71-86.

Burnett, C. M., \& Kogan, V. (2014). Ballot (and voter) "exhaustion" under instant runoff voting: An examination of four ranked-choice elections. Electoral Studies, 37, 41-49.

Cole, R. L., Taebel, D. A., \& Engstrom, R. L. (1990). Cumulative voting in a municipal election: A note on voter reactions and electoral consequences. Western Political Quarterly, 43(1), 191-199.

Delli Carpini, M. X., \& Keeter, S. (1996). What Americans know about politics and why it matters. London: Yale University Press.

Donovan, T., Tolbert, C., \& Gracey, K. (2016). Campaign civility under preferential and plurality voting. Electoral Studies, 42, 157-163.

Donovan, T., Tolbert, C., \& Gracey, K. (2019). Selfreported understanding of ranked-choice voting. Social Science Quarterly, 100(5), 1768-1776.

FairVote. (2020). Data on Ranked Choice Voting. FairVote. Retrieved from https://www.fairvote.org/data_on_ rcv\#research_snapshot

Farrell, D. M., \& McAllister, I. (2006). Voter satisfaction and electoral systems: Does preferential voting in candidate-centred systems make a difference? European Journal of Political Research, 45(5), 723-749.

Fortin, J. (2020, February 10). Why ranked-choice voting is having a moment. The New York Times. Retrieved from https://www.nytimes.com/2020/02/ 10/us/politics/ranked-choice-voting.html

Grofman, B., \& Feld, S. L. (2004). If you like the alternative vote (aka the instant runoff), then you ought to know about the coombs rule. Electoral studies, 23(4), 641-659.

Horowitz, D. L. (2000). Ethnic groups in conflict. Berkeley, CA: University of California Press.

Imai, K., Keele, L., Tingley, D., \& Yamamoto, T. (2011). 
Unpacking the black box of causality: Learning about causal mechanisms from experimental and observational studies. American Political Science Review, 105(4), 765-789.

Karpowitz, C. F., \& Pope, J. C. (2015). Who caucuses? An experimental approach to institutional design and electoral participation. British Journal of Political Science, 45(2), 329-351.

Kimball, D. C., \& Anthony, J. (2016). Voter participation with ranked choice voting in the united states. Paper presented at the Annual Meeting of the American Political Science Association, September 1-4 2016, Philadelphia, PA, United States.

Kimball, D. C., \& Kropf, M. (2005). Ballot design and unrecorded votes on paper-based ballots. Public Opinion Quarterly, 69(4), 508-529.

Kimball, D. C., \& Kropf, M. (2016). Voter competence with cumulative voting. Social Science Quarterly, 97(3), 619-635.

Knack, S., \& Kropf, M. (2003). Voided ballots in the 1996 presidential election: A county-level analysis. The Journal of Politics, 65(3), 881-897.

Lau, R. R., \& Redlawsk, D. P. (2006). How voters decide: Information processing in election campaigns. Cambridge: Cambridge University Press.

McDaniel, J. A. (2016). Writing the rules to rank the candidates: Examining the impact of instant-runoff voting on racial group turnout in San Francisco mayoral elections. Journal of Urban Affairs, 38(3), 387-408.

McGinn, E. (2020). Rating rankings: Effect of instant runoff voting on participation and civility. Unpublished manuscript. Retrieved from http://eamonmcginn. com.s3-website-ap-southeast-2.amazonaws.com/ papers/IRV_in_Minneapolis.pdf

Neely, F., Blash, L., \& Cook, C. (2006). An assessment of ranked-choice voting in the San Francisco 2005 election. San Francisco, CA: Public Research Institute. Retrieved from https://www.policyinteractive. org/public/SFSU-IRVFinalReport2005.pdf

Neely, F., \& Cook, C. (2008). Whose votes count? undervotes, overvotes, and ranking in San Francisco's instant-runoff elections. American Politics Research, 36(4), 530-554.

Neely, F., \& McDaniel, J. (2015). Overvoting and the equality of voice under instant-runoff voting in San Francisco. California Journal of Politics and Policy, 7(4). https://doi.org/10.5070/P2cjpp7428929

Redlawsk, D., Bowen, D., \& Tolbert, C. (2008). Comparing caucus and registered voter support for the 2008 presidential candidates in lowa. PS: Political Science and Politics, 41(1), 129-138.

Santucci, J. (2017). Party splits, not progressives: The origins of proportional representation in American local government. American Politics Research, 45(3), 494-526.

Sinclair, D., \& Alvarez, R. M. (2004). Who overvotes, who undervotes, using punchcards? Evidence from Los Angeles county. Political Research Quarterly, 57(1), 15-25.

Tomz, M., \& Houweling, R. P. V. (2003). How does voting equipment affect the racial gap in voided ballots? American Journal of Political Science, 47(1), 46-60.

Verba, S., Schlozman, K. L., \& Brady, H. E. (1995). Voice and equality: Civic voluntarism in American politics. Cambridge, MA: Harvard University Press.

Wattenberg, M. P., McAllister, I., \& Salvanto, A. (2000). How voting is like taking an SAT test: An analysis of American voter rolloff. American Politics Quarterly, 28(2), 234-250.

\section{About the Author}

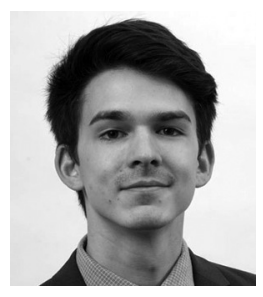

Joseph A. Coll is a Doctoral Candidate and Instructor in the Political Science Department at the University of lowa. His research focuses on how election rules and administration shape the electoral behavior and representation of voters, primarily defined along age, ethnic, racial, and socioeconomic lines. Research interests also include political methodology, public policy, and public opinion. His work has recently been published in American Politics Research, with works currently under-review elsewhere. 